\title{
Analysis of the Factors for Displacement of Earth Retaining Wall with Twin-Stepped Construction
}

\section{Seiya Sakuma, Kazuki Maehara, Takahiro Funatsu, Akihiro Hamanaka, Takashi Sasaoka, Hideki Shimada}

Department of Earth Resources Engineering, Faculty of Engineering, Kyushu University, Fukuoka, Japan

Email: sakuma@aoyamakiko.co.jp

How to cite this paper: Sakuma, S., Maehara, K., Funatsu, T., Hamanaka, A., Sasaoka, T. and Shimada, H. (2019) Analysis of the Factors for Displacement of Earth Retaining Wall with Twin-Stepped Construction. World Journal of Engineering and Technology, 7, 114-121.

https://doi.org/10.4236/wjet.2019.71007

Received: December 14, 2018

Accepted: January 15, 2019

Published: January 18, 2019

Copyright $\odot 2019$ by author(s) and Scientific Research Publishing Inc. This work is licensed under the Creative Commons Attribution International License (CC BY 4.0).

http://creativecommons.org/licenses/by/4.0/

c) (i) Open Access

\begin{abstract}
The demand for specific earth retaining wall method is increasing, along with the advancement and overcrowding of underground space use, such as the presence of close structures, in an urban area. The method is named stepped-twin retaining wall. The feature of this method is to have inner and outer retaining walls and excavate the ground by two-step in order to minimize the effect of the excavation on neighboring existing structures. However, the design of the earth retaining wall is currently carried out by individual engineers based on their own experience. Therefore, it is crucial that the standard method of retaining wall using a two-step construction is established. As the first step toward the standardization, evaluation of factors affecting the ground behavior of the earth retaining wall was carried out. In particular, we picked up four major considerable factors, which are horizontal distance between the outer and inner walls, depth of outer wall embedment, mechanical properties of soil. The evaluation was done by using two dimensional FEM analysis and the results were summarized to make clear the effect of each factor.
\end{abstract}

\section{Keywords}

Excavation, Behavior, Earth Retaining Wall, Finite Element Method

\section{Introduction}

Recently, congestion of underground structures has occurred with the increases of utilization of underground space in urban areas. Therefore, in the new development of the underground, it is required not to affect adjacent existing structures. In order to cope with this, the method named earth stepped-twin retaining wall is increasing. However, the design of the earth retaining wall is currently 
carried out by individual engineers based on their own experience. Therefore, it is crucial that the standard method of earth stepped-twin retaining wall is established.

\section{Earth Stepped-Twin Retaining Wall}

The earth stepped-twin retaining wall is one of the methods of the retaining wall method applied when the height of the foundation bottom of the structure is different in a plane or when the existing structure is buried under the ground [1]. A schematic diagram of earth stepped-twin retaining wall is shown in Figure 1 . As shown in this figure, the outer and inner walls are constructed to prevent the collapse of earth and sand. As a feature of the earth stepped-twin retaining wall, it is possible to reduce the amount of excavation concerning construction and the amount of steel material of earth retaining support, and it is not necessary to excavate unnecessary parts. Examples of applications include construction when the excavation depth differs depending on the shape of the underground structure, temporary working space in the absence of plants and materials on the ground, countermeasures against rebound by buffer excavation, and the like.

\section{Numerical Modeling}

Two dimensional FEM analysises are used for numerical analysis of earth stepped-twin retaining wall. Earth retaining walls and struts are beam elements, and the ground is an elastoplastic body conforming to the Mall-Coulomb breaking standard [2]. Also, in order to consider the friction between the ground and the earth retaining wall, a joint element is provided [3]. The analysis model is shown in Figure 2. This analysis model is an axis-symmetry model of half section and performs a step excavation considering the construction process. In particular, we picked up three major considerable factors, which are horizontal distance between the outer and inner walls, depth of the outer wall embedment, and mechanical properties of soil (Figure 3). The input physical property values of soil and earth retaining member used in this analysis are shown in Table 1 and Table 2 [4] [5].

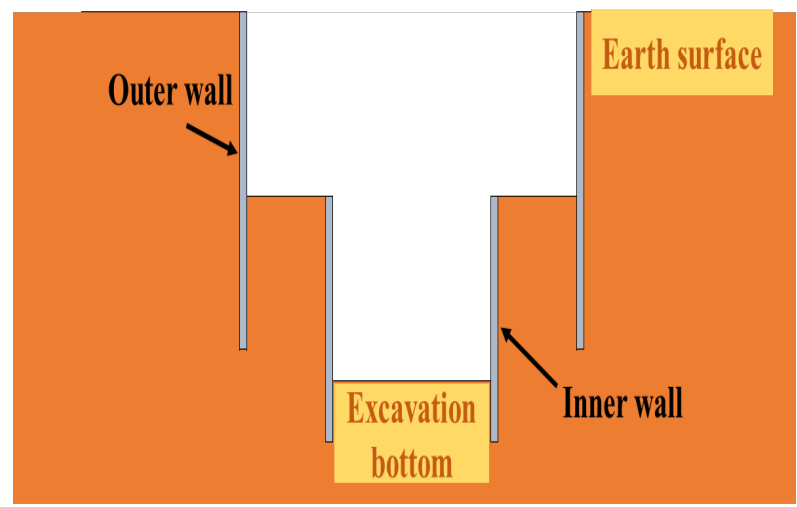

Figure 1. Schematic diagram of earth stepped-twin retaining wall. 


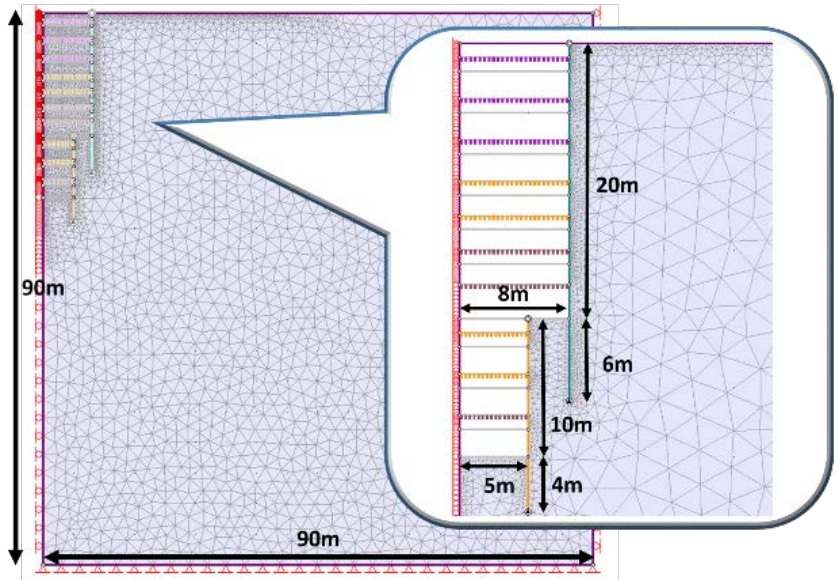

Figure 2. Model of earth stepped-twin retaining wall.

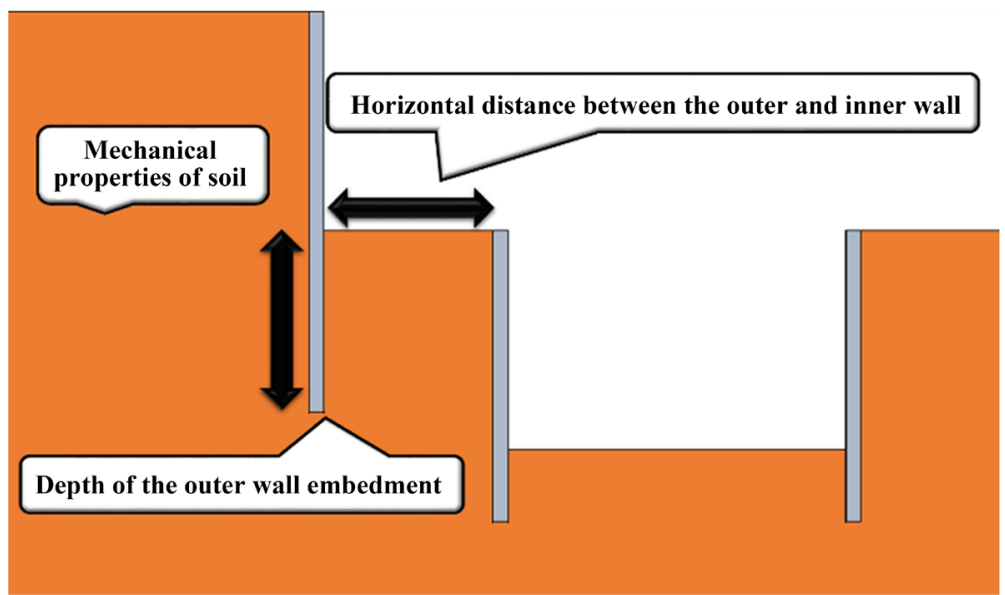

Figure 3. Factors examined by numerical modeling.

Table 1. Physical and mechancial properties of soil.

\begin{tabular}{cccccc}
\hline & $\begin{array}{c}\text { Unit weight } \\
\gamma\left(\mathrm{MN} \cdot \mathrm{m}^{3}\right)\end{array}$ & $\begin{array}{c}\text { Modulus of } \\
\text { deformation } \\
E(\mathrm{MPa})\end{array}$ & $\begin{array}{c}\text { Poisson's ratio } \\
V(-)\end{array}$ & $\begin{array}{c}\text { International } \\
\text { friction angle } \\
\varphi\left({ }^{\circ}\right)\end{array}$ & $\begin{array}{c}\text { Cohesion } \\
c(\mathrm{MPa})\end{array}$ \\
\hline Sandy soil & 0.017 & 12 & 0.30 & 35 & 0 \\
Cohesive soil & 0.014 & 25 & 0.40 & 0 & 0.15 \\
\hline
\end{tabular}

Table 2. Physical and mechanical properties of earth retaining member.

\begin{tabular}{ccccc}
\hline & $\begin{array}{c}\text { Young's Modulus } \\
E(\mathrm{GPa})\end{array}$ & $\begin{array}{c}\text { Poisson's ratio } \\
V(-)\end{array}$ & $\begin{array}{c}\text { Cross-sectional } \\
\text { area } \\
A\left(\mathrm{~cm}^{2}\right)\end{array}$ & $\begin{array}{c}\text { Geometrical } \\
\text { moment of inertia } \\
I\left(\mathrm{~cm}^{4}\right)\end{array}$ \\
\hline Outer wall SMW & 200 & 0.34 & 187.2 & 114,000 \\
Inner wall Sheet pile & 200 & 0.30 & 267.6 & 63,000 \\
$1^{\text {st }}, 2^{\text {nd }}, 3^{\text {rd }}$ Strut & 200 & 0.20 & 34.9 & 5,767 \\
$4^{\text {th }}, 5^{\text {th }}, 8^{\text {th }}$ and $9^{\text {th }}$ Strut & 200 & 0.20 & 51.6 & 11,667 \\
$6^{\text {th }}, 7^{\text {th }}$ and $10^{\text {th }}$ Strut & 200 & 0.20 & 65.9 & 19,667 \\
\hline
\end{tabular}




\section{Results and Discussion}

\subsection{Influence of Horizon Distance between the Outer and Inner Wall}

Figure 4 shows the maximum amount of horizontal displacement of the inner wall during the final excavation when the horizontal distance between the outer and inner wall is changed from $2 \mathrm{~m}$ to $7 \mathrm{~m}$. The figure shows that as the horizontal distance between the outer and inner wall decreases, the maximum horizontal displacement of the inner wall increases. Further, at the horizontal distance of $5 \mathrm{~m}$, the behavior of the graph of the maximum horizontal displacement is changed. According to the tunnel standard specification document [6], the lateral pressure acting on the inner wall in earth stepped-twin retaining wall method is different by whether the active slip line enters inside or outside of the excavated bottom of the outer wall. When the active slip line enters inside the excavated bottom of the outer wall, just the lateral pressure acting from the backfill of the inner wall is taken into consideration as with the general earth retaining wall. When the active slip line enters outside the excavated bottom of the outer wall, the soil load in the area surrounded by the outer wall and the active slip line is considered as the surcharge applied to the lateral pressure of the inner wall. Here, the active slip line can be expressed as a slope on of $45^{\circ}+\varphi / 2$, and $\varphi$ is the internal friction angle of the soil. In this analysis model, if we subtract the active slip line at the slope of $45^{\circ}+\varphi / 2$ from the excavation bottom of the inner wall, under the sandy soil condition, when the horizontal distance is less than $5.2 \mathrm{~m}$, the backfill of the outer wall is included in the active slip line. Therefore, as the horizontal distance becomes smaller as shown in the figure, it is considered that the lateral pressure of the inner wall becomes larger, which affects the displacement of the inner wall.

\subsection{Influence of Mechanical Properties of Soil}

Figure 5 shows the horizontal displacement of the inner wall when the soil is changed. As shown in the figure, it is understood that the horizontal displacement of the inner wall is larger in the sandy soil. This is thought to be due to the fact that the modulus of deformation of sandy soil is smaller than that of cohesive soil. On the other hand, there is no difference in the depth at which the horizontal displacement of the inner wall is the maximum; the maximum horizontal displacement is shown roughly in the middle of the inner wall.

\subsection{Influence of Depth of the Outer Wall Embedment}

Figure 6 shows the relationship between the depth of the outer wall embedment and the maximum horizontal displacement of the inner wall. The horizontal distance between the outer and inner wall is $3 \mathrm{~m}$. It can be seen that the maximum horizontal displacement of the inner wall increases as the depth of the outer wall embedment decreases for both sandy soil and cohesive soil. This indicates that the lateral pressure from the surrounding ground to the inner wall 


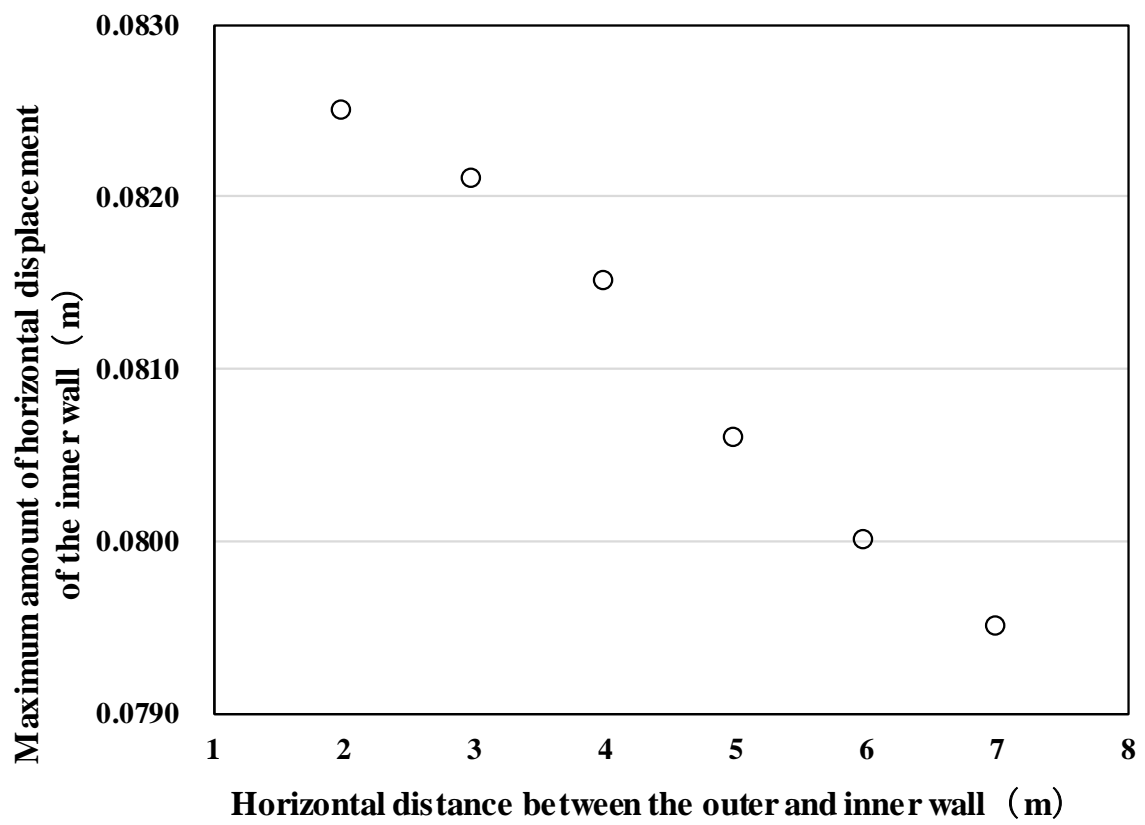

Figure 4. Relationship between horizontal distance and maximum horizontal displacement of the inner wall (sandy soil).

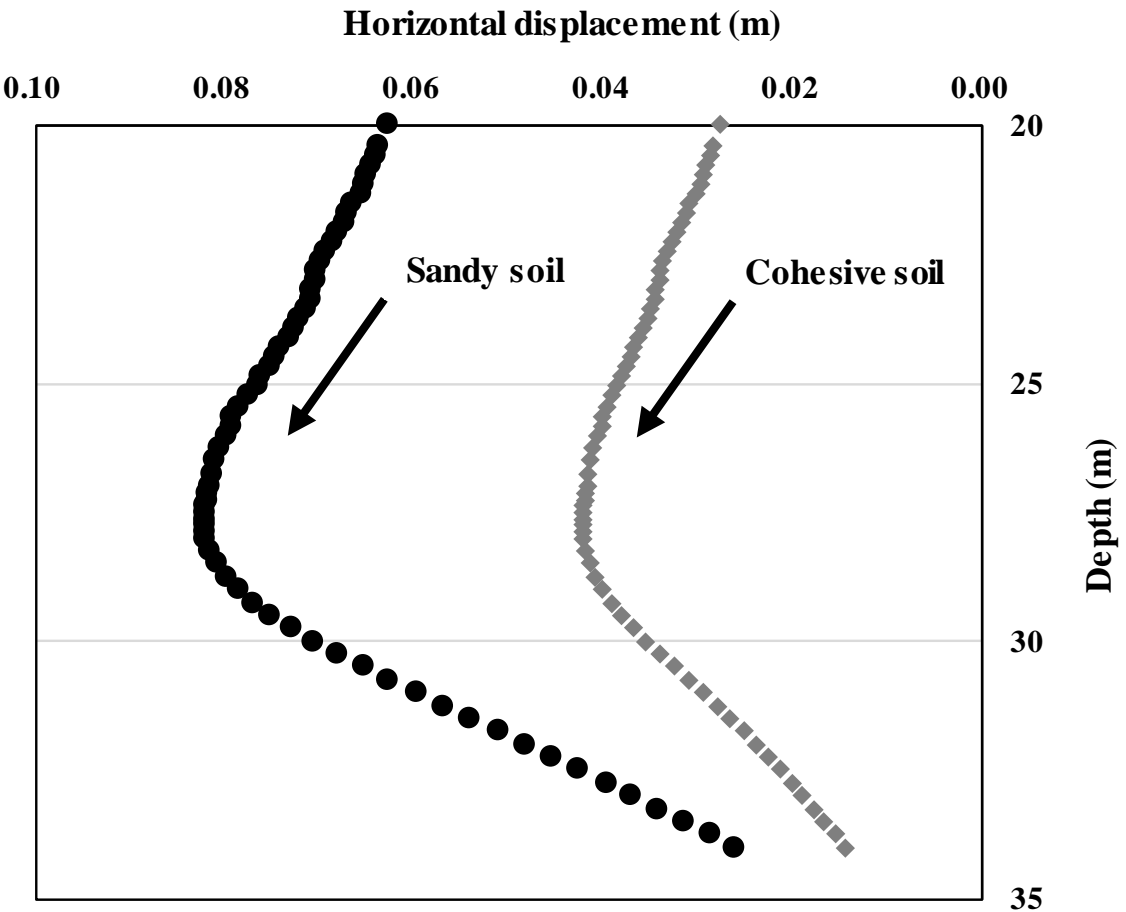

Figure 5. Horizontal displacement of the inner wall in sandy and cohesive soil.

increases as the depth of the outer wall embedment decreases. Also, the behavior of the maximum horizontal displacement is changed with a boundary at $5 \mathrm{~m}$ in the case of sandy soil and $7 \mathrm{~m}$ in the case of cohesive soil (arrow in the figure). It is considered that this is due to the positional relationship between the active slip line and the depth of the outer wall embedment. As an example, Figure 7 shows 


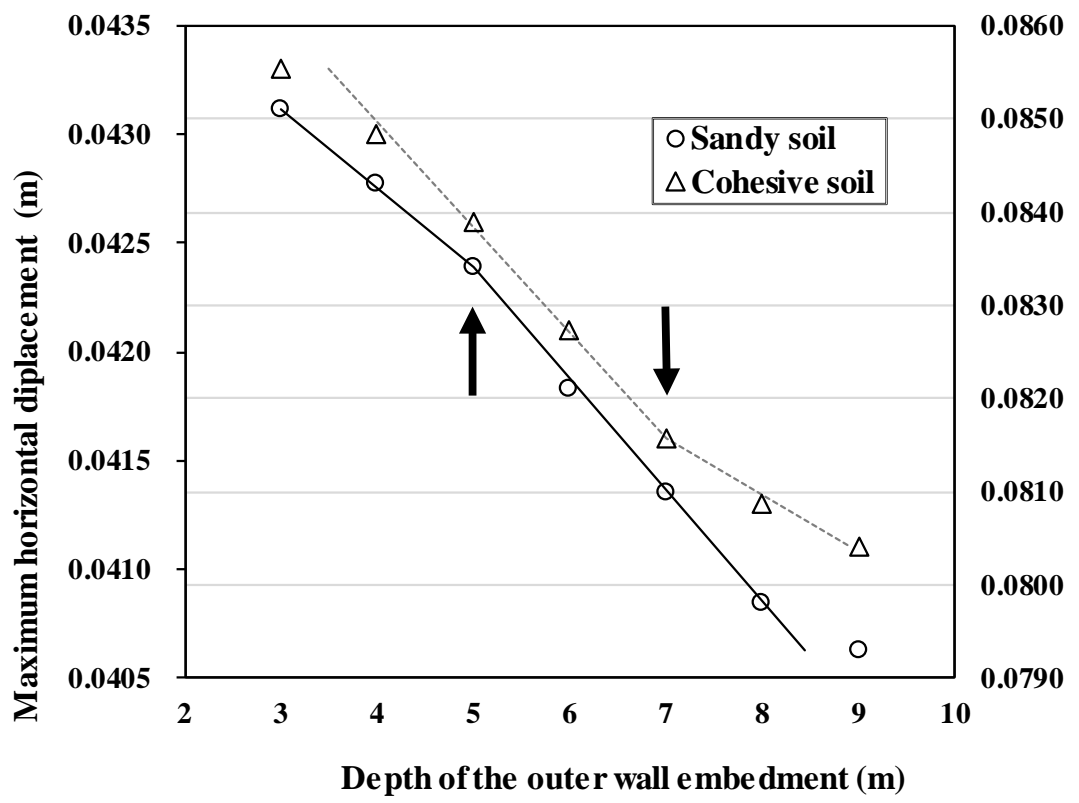

Figure 6. Relationship between the depth of the outer wall embedment and the horizontal displacement of the inner wall.

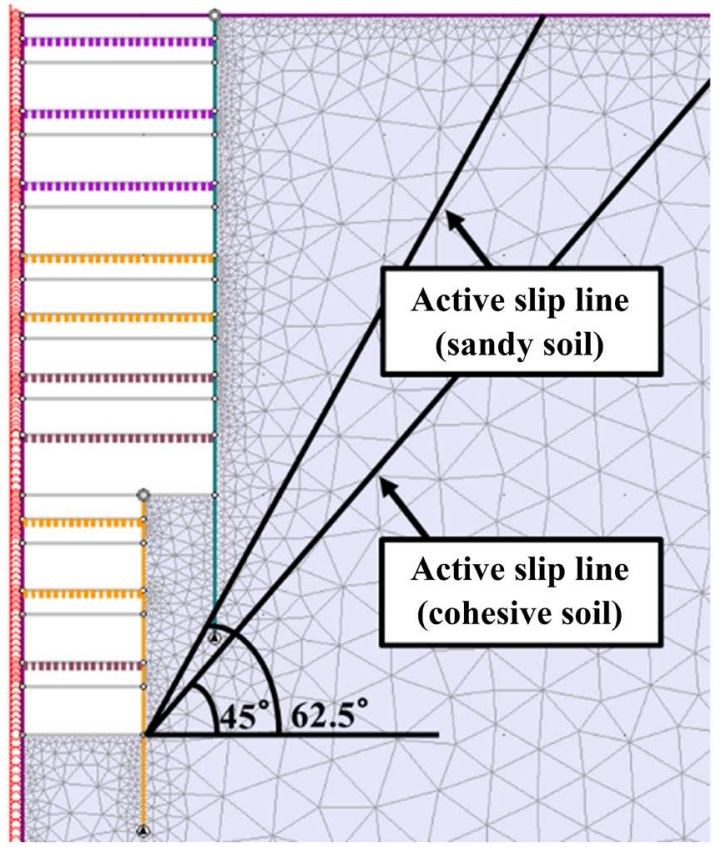

Figure 7. Analysis model and the active slip line.

the positions of the active slip line of sandy soil and cohesive soil when the depth of the outer wall embedment is $6 \mathrm{~m}$. Focusing on the relation between the active slip line and the depth of the outer wall embedment as shown in the figure, the active slip line and the tip of the depth of the outer wall embedment are formed at $5.6 \mathrm{~m}$ in the sandy soil and at $7 \mathrm{~m}$ in cohesive soil. In other words, it is thought that the lateral pressure acting on the inner wall can be reduced when the active slip line and the depth of the outer wall embedment intersect. 


\subsection{The Lateral Pressure Acting on the Inner Wall}

From the results in the previous section, we formulate and generalize the lateral pressure acting on the inner wall in the earth stepped-twin retaining wall by using various parameters. As shown in Figure 8, assuming that the horizontal distance between the outer and inner wall is $D$, the depth of the earth stepped-twin retaining is $H$, and the internal friction angle of the soil is $\varphi$, the arrow indicated by red in the figure can be expressed by $H_{\text {tan }}\left(45^{\circ}-\varphi / 2\right)$. In the case that the active slip line enters outside the excavated bottom of the outer wall, that is, satisfies $D<H_{\tan }\left(45^{\circ}-\varphi / 2\right)$, the soil load in the range surrounded by the active slip line and the outer wall as the lateral pressure of the inner wall is considered as the surcharge. Also, as shown in Figure 9, the arrow indicated by red in the figure

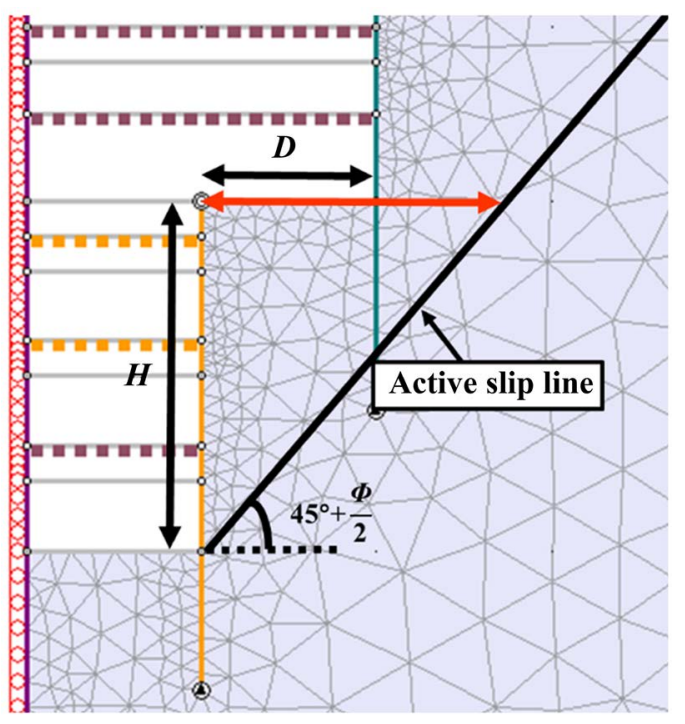

Figure 8. Consideration of the sercharge.

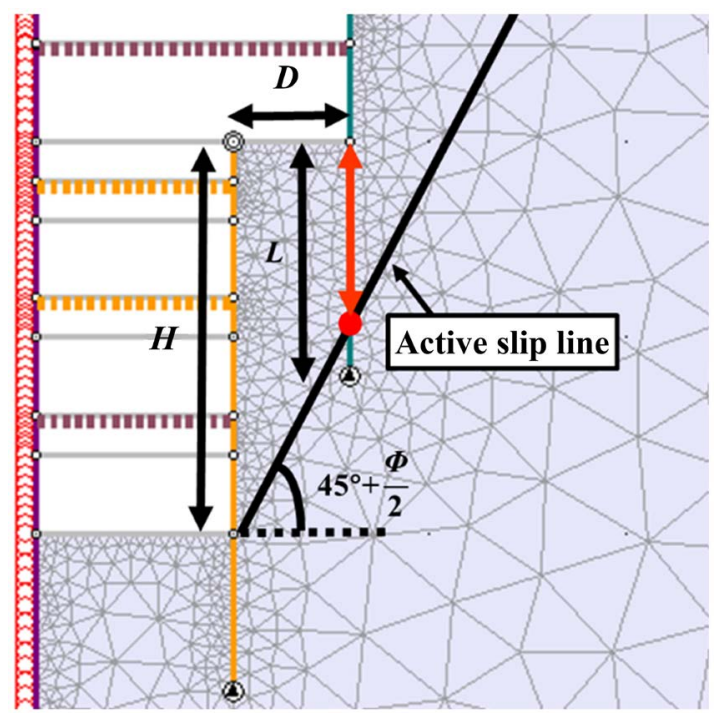

Figure 9. Intersection point (red dot) between active slip line and the depth of the outer wall embedment. 
can be expressed by $H-D_{\tan }\left(45^{\circ}+\varphi / 2\right)$. If the depth of the outer wall embedment is $L$, when the active slip line and the depth of the outer wall embedment have an intersection point, that is, when $L \geq H-D_{\tan }\left(45^{\circ}+\varphi / 2\right)$ is satisfied, the main effect of surrounding ground acting as lateral pressure of the inner wall can be suppressed.

\section{Conclusions}

We investigated various parameters that influence the behavior of inner wall in the earth stepped-twin retaining. The results of this study are shown below.

- If the active slip line enters the outside of the excavated bottom of the outer wall due to the change in horizontal distance, that is, $D$ which is the horizontal distance between the outer and inner wall satisfies $D<H_{\tan }\left(45^{\circ}-\varphi / 2\right)$, since the surchage is considered as the lateral pressure of the inner wall, the influence of the backfill on the displacement of the inner wall is great.

- The influence of the surrounding ground on the inner wall changes due to the change in the depth of the outer wall embedment. When $L$ which is the depth of the outer wall embedment satisfies $L \geq H-D_{\tan }\left(45^{\circ}+\varphi / 2\right)$, since the depth of the outer wall embedment intersects the active slip line, the influence on the displacement of the inner wall from the back ground is small.

In the earth stepped-twin retaining, the horizontal distance between the outer and inner wall and the depth of the outer wall embedment are important factors affecting the inner wall. Also, since the inclination of the active slip line varies with the difference of soil quality, it can be said that it is necessary to design and consider each factor comprehensively.

\section{Conflicts of Interest}

The authors declare no conflicts of interest regarding the publication of this paper.

\section{References}

[1] Shimomura, T., Ueno, T. and Takeda, S. (2009) Excavation and Earth Retaining-Design of Temporary Structures. Taisei Corporation, Kyoto, 213-253.

[2] Japanese Geotechnical Society (1999) Practical Business of Numerical Analysis in Geotechnical Engineering. 189-226.

[3] Honda, T. (1998) Setting Method of Joint Element in Earth Retaining FEM Analysis, Soil and Bases. Soil Engineering Society, 39-40.

[4] Nippon Steel and Sumitomo Metal Corporation (2013) Handbook of Construction Materials. Kyoto, 22.

[5] Product Dimensions of H-Shaped Steel. Marufuji Sheet Piling Co., Ltd. http://www.mrfj.co.jp/product/hgtku/

[6] Japan Society of Civil Engineers and Committee of Tunnel Engineering (2016) Standard Specifications for Tunneling. 200-201. 